\title{
Toxicological analysis of acute pesticides poisoning among Moroccan population
}

\author{
Bouchra Birich ${ }^{1,2^{*}}$, Souad El Hajjaji ${ }^{1}$, Mohamed Ghandi ${ }^{2}$, Naima Ait Daoud ${ }^{2}$, Mustapha Ouaide ${ }^{2}$, Narjis Badrane ${ }^{2}$, and \\ Rachida Soulaymani Bencheikh ${ }^{2,3}$ \\ ${ }^{1}$ Mohammed V University, Faculty of sciences, LS3MN2E-CERNE2D, Department of chemistry, 4 street Ibn Battouta B.P. 1014 RP, \\ Rabat, Morocco \\ ${ }^{2}$ The Poison Control and Pharmacovigilance Center of Morocco (CAPM), Street Lamfedel Cherkaoui, Instituts, Madinate Al Irfane, \\ B.P. 66 71. Rabat, Morocco \\ ${ }^{3}$ Mohammed V University, Faculty of Medicine and Pharmacy, Impasse Souissi, Rabat, Morocco
}

\begin{abstract}
The aim of this study is to evaluate the importance of toxicological analysis in acute intoxications by pesticides through the experience of the laboratory of the Poison Control and Pharmacovigilance Center of Morocco (CAPM). This is a retrospective study from January 2014 to September 2020, concerning suspected pesticides poisoning cases. The cholinesterase activity was measured in whole blood and the chromatographic analyzes (GC-MS and LC-MS-MS) were conducted in blood, urine and gastric lavage fluid. In this study, 398 tests were involved. The median age of the patients was 14 with an interquartile range of [4-26 years]. The sex ratio $(\mathrm{F} / \mathrm{M})$ was 1.5 . The requests were from the region of Rabat-SaléKénitra in $82.8 \%$ of cases (north-western Morocco). The cholinesterase activity measurement was performed for 295 patients with low values in $3.7 \%$ of cases. The toxicological screening by GC-MS and LC-MS-MS detected the pesticide responsible of poisoning in 62 cases as insecticides in $38 \%$ of cases, redenticides (33\% of cases) and herbicides (5\% of cases). Toxicological analysis plays an essential role in the diagnosis and the management of acute pesticides poisoning. Interpretation of results is carried over by analyst with close cooperation with clinical toxicologist.
\end{abstract}

\section{Introduction}

Pesticides are used across the world to protect crops, plants in agriculture, gardens or domestics, against insects, rodents or any pests threating the public health. Indeed, this chemical molecules causes above of 5 million of intoxications annually, according to the World Health Organization (WHO) [1]. Toxicity effects depend on the dose of the substance consumed and the health stat of the poisoned person. The effects are reduced with time when the exposition is limited or removed. The recovery is possible if no health complication has been occurred [2]. The misuse of the pesticides is the main cause of this type of intoxication. Therefore, the suicide is the main cause worldwide [1]. In Morocco, the pesticides intoxications are in the front line among all intoxications according to the Poison Control and Pharmacovigilance Centre of Morocco (CAPM). The same center reported, 11196 acute pesticides poisoning cases, in Morocco from 2008 to 2016 [3].

Nowadays, analytical methods, especially chromatographic ones, facilitate the detection and the quantification of pesticides in biological samples and contribute in the diagnostic and the management of acute poisoning cases. Therefore, the aim of this study is to highlight the role of the toxicological analysis in the management of acute intoxication by pesticides among Moroccan population.

\section{Method}

This is a retrospective study conducted in Morocco describing 398 cases of acute poisoning with pesticides reported to the laboratory of the CAPM between January 2014 and September 2020. The data collected was from the laboratory registration system of analysis requests received from Moroccan hospitals. We were interested to describe the requests using the demographic characteristics (age, sex, date of analysis, provenance) and the toxicological characteristics (symptomatology and pesticide name). Classification of pesticides was performed based on the chemical composition.

After the reception, the sample is labeled and directed to extraction before the chromatographic analysis. For the blood, a cholinesterasic measurement is operated before and centrifuged to acquire the plasma for the next step. In the study period, this measurement used two technics; Test-mate ChE Cholinesterase Test System (Model 400) and $\mathrm{ChE}$ check mobile. After a liquid-liquid extraction, a first large screening by Liquid Chromatography with

\footnotetext{
*Corresponding author: bouchra.birich1@gmail.com
} 
tandem mass spectrometry (LC-MS-MS) and Gas Chromatography with mass spectrometry (GC-MS), then a confirmation step with the specific mass ion.

\subsection{Apparatus}

\subsubsection{GC-MS}

The analysis are executed with the 680 PerkinElmer Clarus GC-MS and a column RESTEK RXI ${ }^{\circledR} 5 \mathrm{~ms}(30 \mathrm{~m}$ $\times 0.25 \mathrm{~mm}, 250 \mathrm{m \mu}$ ). The carrier gas is helium with a flow rate: $0.1 \mathrm{ml} / \mathrm{min}$.

Mass spectrometry detector used an electron ionization mode with an ionization energy of $70 \mathrm{eV}$. The ion source temperature was $250^{\circ} \mathrm{C}$.

\subsubsection{LC-MS-MS}

3200Q TRAP-AB Sciex Instrument was used with analysis time of 15 minutes and injection volume of $10 \mu \mathrm{l}$. The aqueous phase is composed by water, ammonium formate $(1 \mathrm{M})$ and formic acid $(0.1 \mathrm{M})$. For the organic phase, we replaced the water by the methanol.

\subsubsection{Solvents}

The chromatographic analysis used methanol (99.9\%) and the ammonium format (99.99\%) purchased from Sigma Aldrich $^{\circledR}$. We purchased Formic acid (99\%) and dichloromethane (99.9\%) from Carlo Ebra, promanol-2 (99.9\%) from Panreac and heptane (99\%) from Scharlar.

\subsubsection{Extraction}

We added one milliliter of the sodium carbonate buffer to $1 \mathrm{ml}$ of the sample (plasma, urine or gastric liquid). Then, $5 \mathrm{ml}$ of the extraction solvent (Propanol, Dichloromethane and formic acid) was added to the preparation after a quick agitation [4]. The whole is centrifuged for $10 \mathrm{~min}$. The eluent is evaporated under nitrogen gas at $45^{\circ} \mathrm{C}$. The recovery from the evaporation tubes is done with methanol. Only $10 \mu \mathrm{l}$ are injected into the GC-MS and the LC-MS-MS.

\subsubsection{Data analysis}

The data analysis of GC-MS was done with TurboMass ${ }^{\circledR}$ software version 6.0 and the NIST library version 2008. The LC-MS-MS results were given by Analyst $\AA$ 1.6.2 software (version 2013), using Multi Reaction Monitoring (MRM) of each molecule, retention time $\left(t_{R}\right)$ and the concordance in the library.

\section{Results}

\subsection{Demographic characteristics of the study population}

398 cases of suspected pesticides poisoning from Moroccan hospitals were studied. The median age of the patients was 14 years with an interquartile range of [4-26 years]. The poisoning cases concerned children in accidental circumstance in $51 \%$ of all cases (Figure 1).

We found that $60 \%$ of the patients are female (Figure2) with a sex ration $(\mathrm{F} / \mathrm{M})$ equal to 1.5 . From 2014 to September 2020, the number of cases varied from 47 to 73 per year (Figure 3 ). Because of the proximity, almost all the cases $(82.8 \%)$ was from north-western of Morocco (Rabat-Salé-Kénitra).

Distribution of requests for pesticide analysis by age group

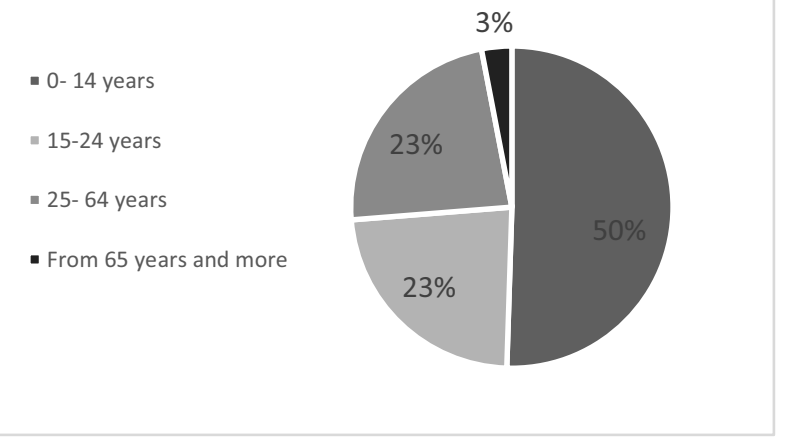

Fig. 1. Distribution of requests for pesticide analysis by age group.

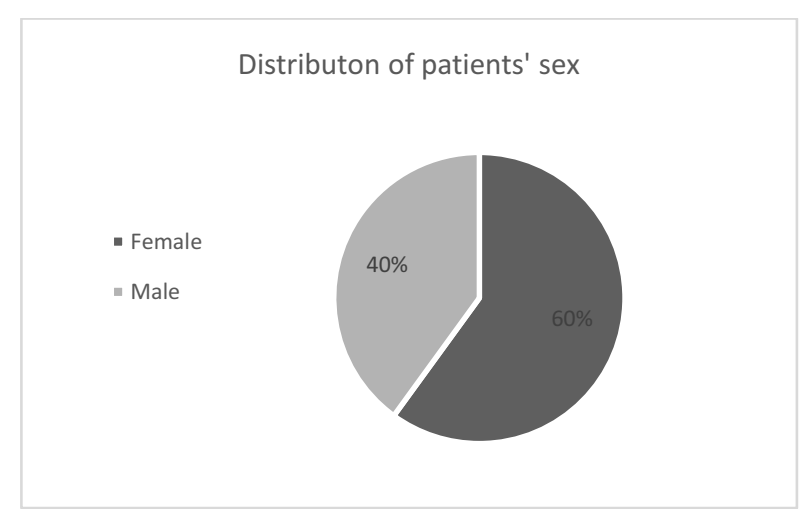

Fig. 2. Distribution of patients' sex

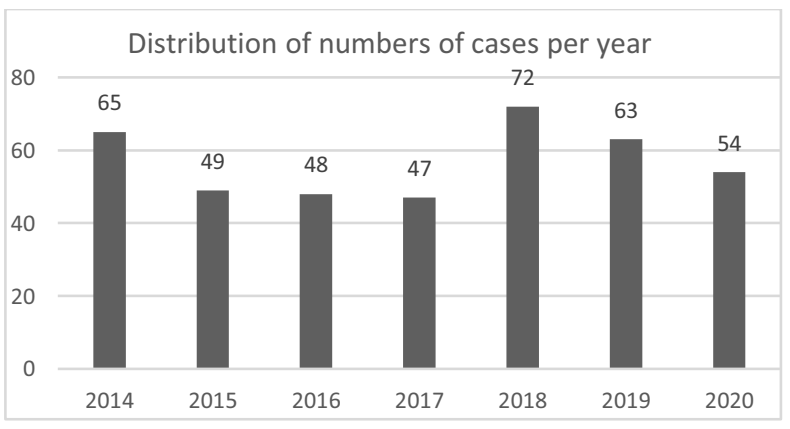

Fig. 3. Distribution of numbers of cases per year 


\subsection{Cholinesterase measurement}

This measurement is systematically done for any suspicion of poisoning by organophosphates $(\mathrm{Op})$ or carbamates (Cbt). We did 295 measurement with two photometric technics, Method 1 (M 1) and Method 2 (M2), with the same principle. Statistical analysis of the results is done (Table 1).

For the Test System (Model 400) technic, the results are given as percentages. A severe intoxication indicates values between $25 \%$ and $0 \%$. It may be important to consider values from $25 \%$ to $50 \%$ because it directs to a probable severe poisoning, repetition of the measurement is recommended in this situation.

The $\mathrm{ChE}$ check mobile, an interval of normal values is followed. For AChE the results must be between 33.0 and $49.4 \mathrm{U} / \mathrm{gHb}$. The $\mathrm{BChE}$ is normal if its values are up to1623. and under $3861 \mathrm{U} / \mathrm{L}$.

A correlation between age, $\mathrm{AChE}$ and $\mathrm{BChE}$ was done. We illustrate the correlation for the two methods in the figures (Figures 4 to 9). The strongest correlation is verified with a coefficient correlation close to1 or -1 . When the variables are not correlated, the coefficient is near to zero. For our results, the coefficients of correlation are respectively; 0.0002, 0.0167, 0.3196, 0.0004, 0.0722 and 0.2393 . Then, no correlation is observed.

The laboratory received blood samples more than once for outcome cholinesterase monitoring.

Table 1. Statistical analysis of AChE and BChE measured in blood by two methods

\begin{tabular}{|c|c|c|c|}
\hline Parameters & Statistics & F & M \\
\hline \multirow{4}{*}{ Age (years) } & \begin{tabular}{|l}
$\mathrm{N}$ \\
\end{tabular} & 129 & 85 \\
\hline & Max & 76 & 78 \\
\hline & Min & 0 & 0.2 \\
\hline & Average & 18 & 18 \\
\hline \multirow{4}{*}{$\begin{array}{l}\text { AChE1 } \\
(\%)\end{array}$} & Max & 94 & 100 \\
\hline & Min & $<10$ & $<5$ \\
\hline & Average & 48.7 & 47.4 \\
\hline & $\begin{array}{l}\text { Standard } \\
\text { deviation }\end{array}$ & 23.3 & 24.3 \\
\hline \multirow{4}{*}{$\begin{array}{l}\text { BChE1 } \\
(\%)\end{array}$} & Max & 100 & 106 \\
\hline & Min & $<10$ & -14 \\
\hline & Average & 60.71 & 54.03 \\
\hline & $\begin{array}{l}\text { Standard } \\
\text { deviation }\end{array}$ & 28.65 & 28.5 \\
\hline \multirow{4}{*}{ AChE2 } & Max & 53.5 & 82.6 \\
\hline & Min & 4.44 & 6.2 \\
\hline & Average & 40.85 & 43.06 \\
\hline & $\begin{array}{l}\text { Standard } \\
\text { deviation }\end{array}$ & 17.7 & 15.23 \\
\hline \multirow[t]{3}{*}{ BChE2 } & Max & 5100 & 5939.8 \\
\hline & Min & 377 & 361.9 \\
\hline & Average & 2310.96 & 2453.6 \\
\hline
\end{tabular}

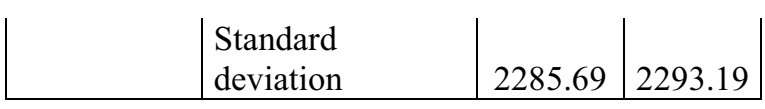

Correlation betwen the age and AChE

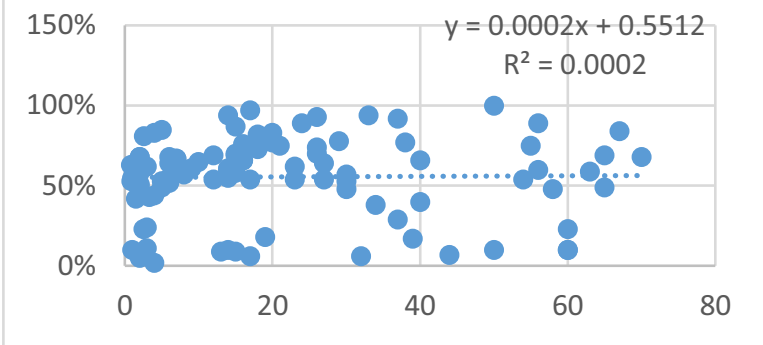

Fig. 4: Correlation between the age and AChE (M 1)

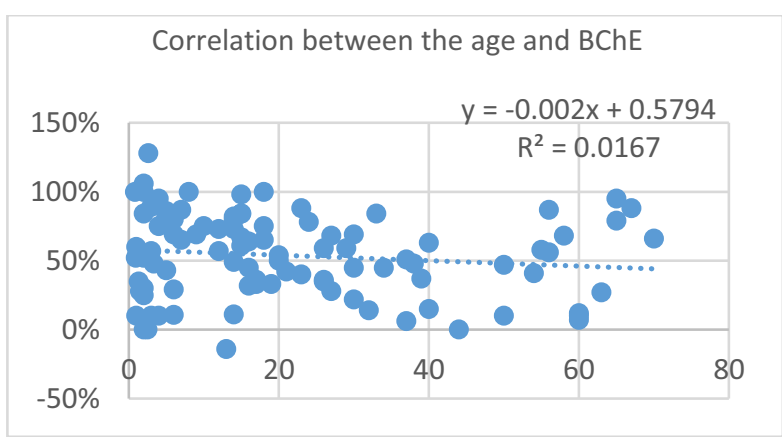

Fig. 5: Correlation between the age and BChE (M1)

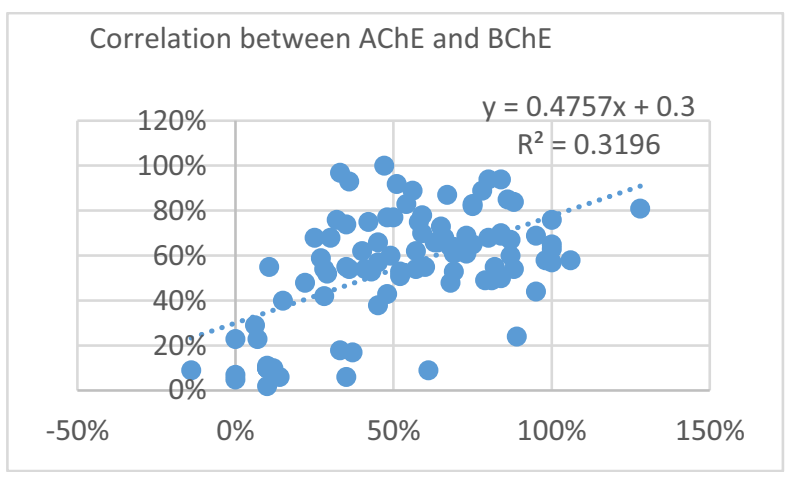

Fig. 6: Correlation between $\mathrm{AChE}$ and $\mathrm{BChE}$ (M 1)

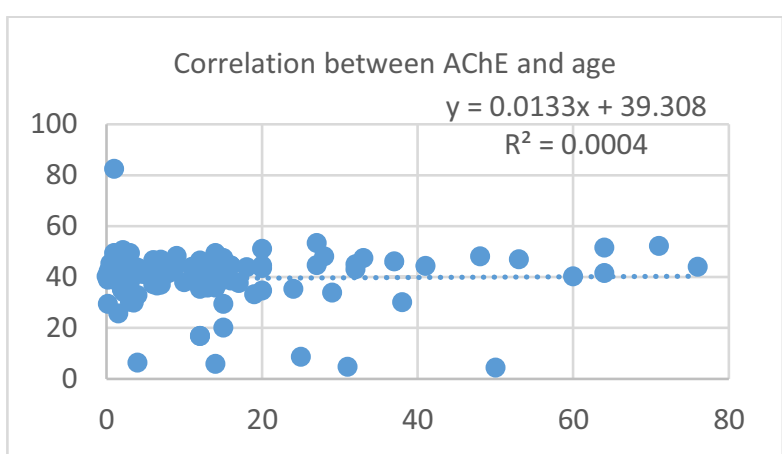

Fig. 7: Correlation between the age and $\mathrm{AChE}$ (M 2) 


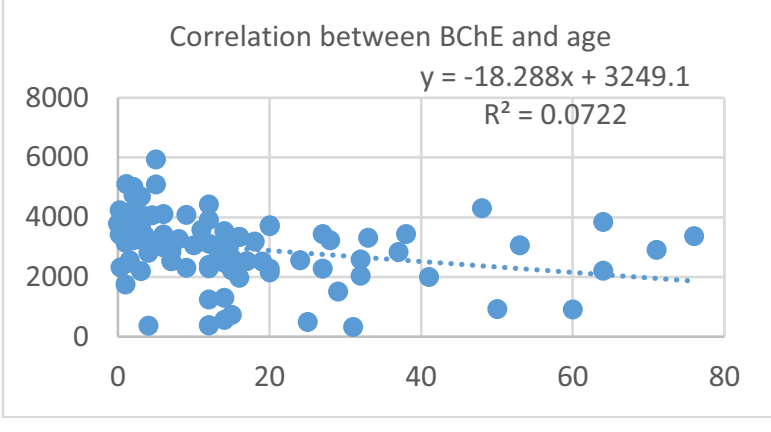

Fig. 8: Correlation between the age and $\mathrm{BChE}$ (M 2)

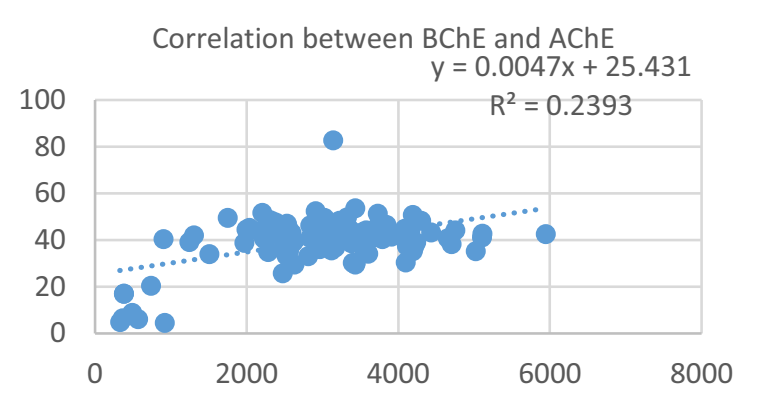

Fig. 9: Correlation between $\mathrm{AChE}$ and $\mathrm{BChE}$ (M 2)

\subsection{Chromatographic analysis}

It is 360 chromatographic analysis. It confirmed the presence of pesticides among 62 poisoned patients.

The results shows families of pesticides responsible of poisoning in 62 cases (Figure 10). The insecticides were the first family (38\%), with Op in $(58 \%)$, Cbt $(33 \%)$ and pyrethroids $(24 \%)$. The rodenticides $(33 \%)$ were in the second range, all the patients were poisoned by the alphachloralose. In the last place, with a percentage of 5 , we have herbicides, $40 \%$ of the poisoning were caused by amitraz.

A liquid-liquid extraction is conducted for a large chromatographic screening. All the results must be confirmed with a specific search, with the mass $\mathrm{m} / \mathrm{z}$ for GC-MC and Multi Reaction Monitoring (MRM) with the software library for LC-MS-MS. All the molecules detected, are listed in the table 2.

As an example, figures 11 and 12 show the detection of alpha-chloralose at $t_{R}=15.75 \mathrm{~min}$ for GC-MS and at 2.04 min for the LC-MS-MS

Pesticides molecules implicated in acute poisoning cases

\section{- Insecticides \\ - Rodenticides \\ - Herbicides}

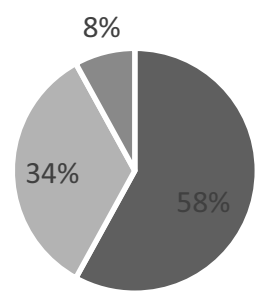

Fig. 10. Pesticides molecules implicated in acute poisoning cases
Table 2. Positive cases poisoned by pesticides

\begin{tabular}{|c|c|c|c|c|}
\hline $\mathbf{N}^{\circ}$ & Sex & Age & Pesticides & $\begin{array}{c}\text { Orientation and } \\
\text { symptomes }\end{array}$ \\
\hline 1 & F & NI* & Carbofuran & $\mathrm{NI}^{*}$ \\
\hline 2 & F & 39 & Carbofuran & NI \\
\hline 3 & $\mathrm{M}$ & 52 & 2,4 d isobutyl ester & Herbicide \\
\hline 4 & $\mathrm{M}$ & 12 & Malathion & NI \\
\hline 5 & $\mathrm{~F}$ & $\mathrm{NI}^{*}$ & Alphachloralose & $\begin{array}{l}\text { Disturbance of } \\
\text { conscience }\end{array}$ \\
\hline 6 & $\mathrm{M}$ & NI* & $\begin{array}{l}\text { Chlorpyriphos, 3,5, } \\
\text { 6-trichloropyridinol }\end{array}$ & Insecticides \\
\hline 7 & F & 18 & $\begin{array}{c}3,5,6- \\
\text { trichloropyridinol }\end{array}$ & Coma \\
\hline 8 & $\mathrm{M}$ & NI* & Deltamethrine & Rodenticide \\
\hline 9 & F & NI* & Chlorpyrifos & Methomyl \\
\hline 10 & $\mathrm{M}$ & 23 & Alphachloralose & Coma \\
\hline 11 & $\mathrm{~F}$ & NI* & Alphachloralose & NI \\
\hline 12 & M & 2 & Chlorpyrifos & $\begin{array}{l}\text { Product with } \\
\text { diazinon }\end{array}$ \\
\hline 13 & $\mathrm{~F}$ & 65 & Alphachloralose & Insecticides \\
\hline 14 & F & NI & $\begin{array}{c}\text { Malathion, } \\
\text { Deltamethrine }\end{array}$ & Product Igatox \\
\hline 15 & F & 17 & $\begin{array}{c}\text { Carbofuran, 3- } \\
\text { hydroxycarbofuran }\end{array}$ & $\begin{array}{l}\text { Blue pouder - } \\
\text { Rodenticide }\end{array}$ \\
\hline 16 & $\mathrm{M}$ & NI & Alphachloralose & Rodenticide \\
\hline 17 & $\mathrm{~F}$ & NI & Malathion, Malaxon & Op \\
\hline 18 & $\mathrm{~F}$ & NI & $\begin{array}{l}\text { MCPA, 2,4d, } \\
\text { printazole }\end{array}$ & NI* \\
\hline 19 & $\mathrm{~F}$ & 1 & Chlorpyrifos & Op \\
\hline 20 & $\mathrm{M}$ & 26 & $\begin{array}{l}\text { Chlorpyriphos, 3,5, } \\
\text { 6-trichloropyridinol }\end{array}$ & Op \\
\hline 21 & $\mathrm{M}$ & 20 & Deltamethrine & NI* \\
\hline 22 & $\mathrm{~F}$ & 19 & Carbofuran & $\mathrm{NI}^{*}$ \\
\hline 23 & $\mathrm{M}$ & $\mathrm{NI}^{*}$ & Deltamethrine & $\mathrm{NI}^{*}$ \\
\hline 24 & F & NI* & Dichlovos & Op \\
\hline 25 & $\mathrm{~F}$ & NI* & Deltamethrine & $\mathrm{NI}^{*}$ \\
\hline 26 & M & 25 & Alphachloralose & NI* \\
\hline 27 & $\mathrm{~F}$ & 1 & 2,4 d isobutyl ester & $\mathrm{NI}^{*}$ \\
\hline 28 & $\mathrm{~F}$ & 14 & Malathion & $\mathrm{NI}^{*}$ \\
\hline 29 & $\mathrm{M}$ & 14 & Amitraz & Amitraz \\
\hline 30 & $\mathrm{M}$ & 6 & $\begin{array}{c}\text { Amitraz, Terbucarb, } \\
\text { Diazinon }\end{array}$ & Hallicunation \\
\hline 31 & $\mathrm{~F}$ & 3 & Terbucarb & $\mathrm{NI}^{*}$ \\
\hline 32 & $\bar{F}$ & 3 & $\begin{array}{c}\text { Dicaraméthyl 2,4 } \\
\text { methyl ester, } \\
\text { Dicamba }\end{array}$ & Coma \\
\hline 33 & $\mathrm{M}$ & NI* & $\begin{array}{l}\text { Chlorpyriphos, 3,5, } \\
\text { 6-trichloropyridinol }\end{array}$ & NI* \\
\hline 34 & $\mathrm{M}$ & 21 & Alphachloralose & Convulsion \\
\hline 35 & $\mathrm{~F}$ & 17 & Diazinon & Resperatory distress \\
\hline 36 & $\mathrm{~F}$ & 27 & Alphachloralose & Rodenticides \\
\hline 37 & $\bar{F}$ & 1.5 & Bifenthrine & $\mathrm{NI}^{*}$ \\
\hline 38 & F & 56 & Malathion & Malathion \\
\hline 39 & $\bar{M}$ & 38 & Alphachloralose & $\mathrm{NI}^{*}$ \\
\hline 40 & $\mathrm{M}$ & 32 & 3-Hydroxycarofuran & NI* \\
\hline
\end{tabular}




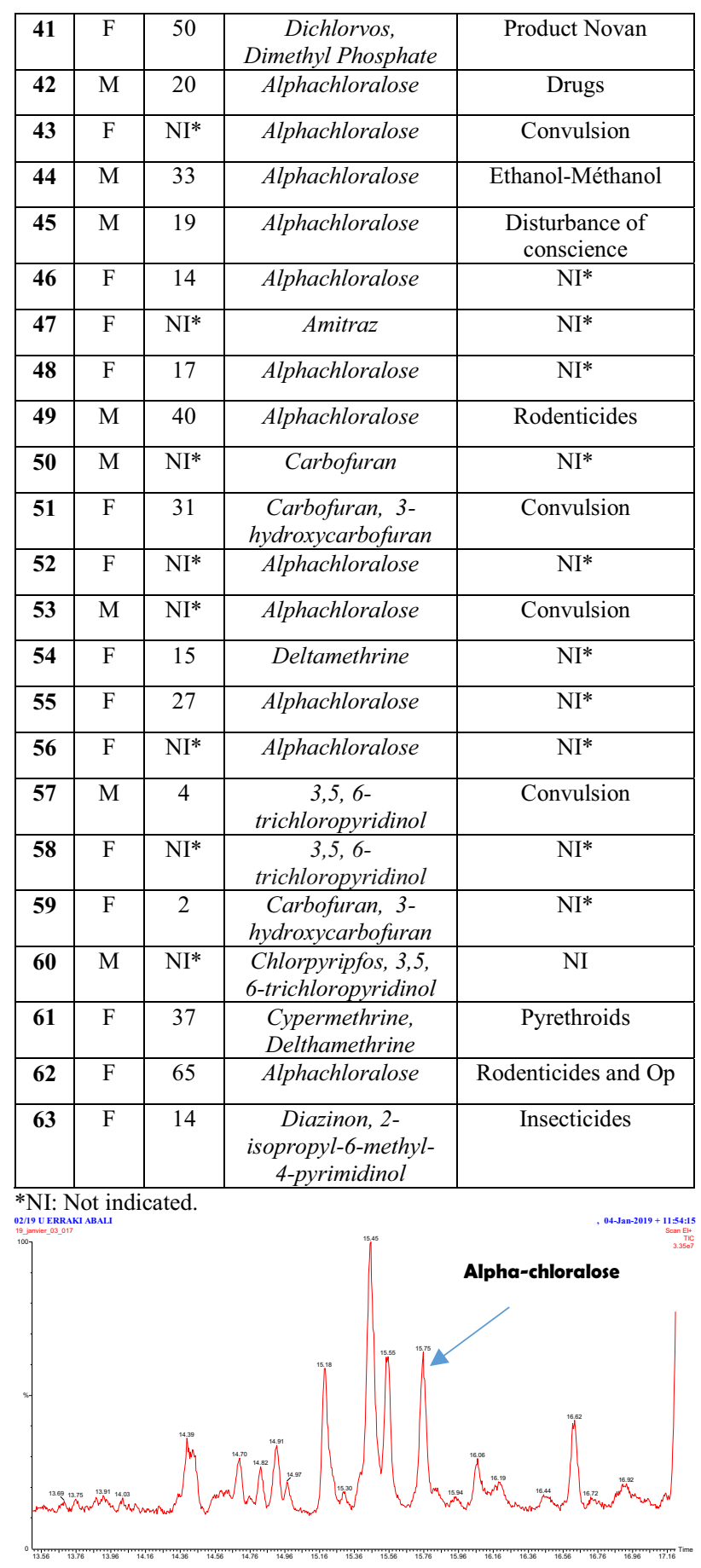

Fig. 11: Detection of Alpha-chloralose by GC-MS

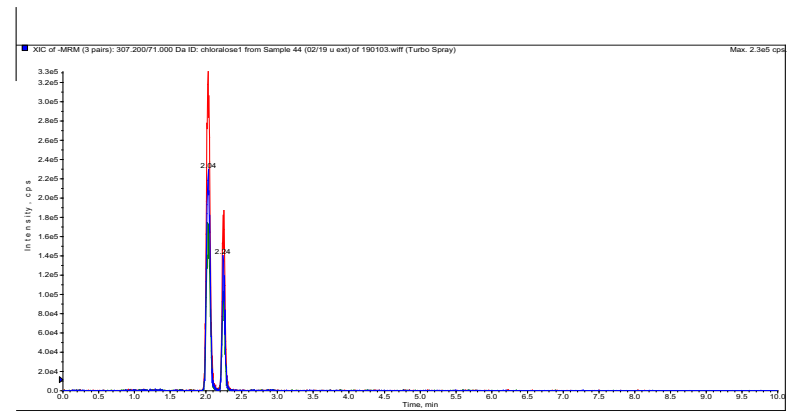

Fig. 12: Detection of Alpha-chloralose by LC-MS-MS

\section{Discussion}

The acute intoxications by pesticides concern more and more the public health over the world. This study show the important number of pesticides' poisoning received in our laboratory. Therefore, the Poison Control Centre of Quebec numbered, between 1995 and 2000, 1518 cases related to pesticide intoxication [5]. In France, 408 notifications were received in the Poison Control Centre between 2012 and 2016 [6].

This work concerns 398 cases of acute poisoning by pesticides with 360 chromatographic analyses received from January 2014 to September 2020 . The most of these intoxications are accidental especially for children. This result is found also in many other studies [7]. For children under 10 years, the bad emplacement of the domestic products and the non-awareness of the parents leads to the poisoning. In the low-income countries, children are in some cases, obliged to work in the agriculture and this exposure enhance the possibility of poisoning. According to the Achour and al. study [7], the females are more likely to commit suicide with pesticides. This results concord with ours. We found that $60 \%$ of analysis requests are from females and the most of them are a voluntary intoxication.

The insecticides are the first type of pesticides causing poisoning in our study. Many retrospectives studies have found similar results [8-9]. These pesticides are provided easily in the market, for domestic consumption in the lowincome countries. The rodenticides, herbicides and fungicides are also among the main causes with less percentage representation. For our work, alpha-chloralose was responsible of $33 \%$ of the cases. This rodenticide is cheaply sold and chosen for committing suicide. Our results are comparable with other studies [10-12].

Cholinesterase measurement guides the diagnosis to Op or Cbt intoxications. The dosage of the AChE is more reliable than the $\mathrm{BChE}$. There is a correlation between the decrease of the AchE value and the severity of the neuromuscular situation. However, the measurement of the $\mathrm{BChE}$ is not consistent because it can decrease naturally with age, sex, during pregnancy, certain pathologies or when taking drugs. For the Op, a specific dosage confirm that the cholinesterase inhibition is caused by pesticides exposition. For carbamates, this inhibition is reversible in 24 hours (except for Aldicarbe) [13].

There is some similarities in the symptology of the poisoning by these different pesticide families. Muscarinic syndrome, nicotinic syndrome and a central syndrome which convulsions, coma, and respiratory distress, are observed for Op and Cbt poisoning with a less pronouncing symptoms for Cbt. Pyrethroids induce ataxia and convulsions. In this situation, a cholinesterase measurement exclude the suspicion of $\mathrm{Op}$ or $\mathrm{Cbt}$ poisoning. Yet, the separative methods decides which the incriminated compound is. It maintains a process to identify the specific patient treatment. Antidotic treatement is based on the administration of atropine sulfate and pralidoxime methyl sulfate for $\mathrm{Op}$ and $\mathrm{Cbt}$ [13].

The CAPM is the only center in the country contributing in the toxicological field adopting the combined 
chromatographic analysis. Gas chromatography is recommended for pesticides' analysis for their volatility. The mass spectroscopy detector performs the identification by the mass $\mathrm{m} / \mathrm{z}$ of the compound with its fragments and a retention time is given according to the temperature program. The liquid chromatography facilitate the separation for thermolabile compounds, with a solvent as mobile phase. For this technic, the mass spectrometry specify the MRMs of the compound according to the library and the retention time $\left(t_{R}\right)$. Combining these two technics for the detection of pesticides, solidify the results transmitted to the hospital to guide the management of patients. The confirmation is operated with chromatographic analysis [14]. This analysis provides additional information about other molecules present in the samples. The multi-systematic method used in this work, detected pesticides in biological sample using a liquid-liquid extraction among 62 patients. Alpha-chloralose was detected in 21 cases, 4 cases only were oriented to this rodenticide and 7 cases had not any indication of the cause of the poisoning. For the alphachloralose cases, chromatographic analysis helped to identify the cause of the poisoning. This ascertainment is found in other studies [15-17]. Nevertheless, the negative results is related to the kinetics of the compounds. The timing of the sampling did not help to detect the molecule before the metabolism or the elimination.

\section{Conclusion}

The diagnosis and treatment of acute intoxication by pesticides is a big challenge for clinicians and analysts. The toxicological analysis helps to perform correctly the analytical process of any poisoning. An awareness program of the population is important to reduce the accidental intoxication especially among children.

\section{Acknowledgments}

The authors want to acknowledge the CAPM for all the facilities given for the research especially the laboratory team.

\section{References}

1. Tova A. Samuels, O. Obare. Sherine, Advances in Analytical Methods for Organophosphorus Pesticide Detection. Pesticides in the modern world-trends in pesticides analysis", 93 (2011).

2. Prise en charge de l'abus de substances psychoactives, terminologie et classification OMS, https://www.who.int/substance_abuse/terminology/ acute intox/fr/

3. M.Windy, J. Ghyslaine, R. Hmimou, N. Rhalem, R. Soulaymani-Bencheikh. Intoxication aigue par les pesticides au Maroc données du centre antipoison et de pharmacovigilance du Maroc (2008-2016), Toxico. Maroc, 39 (2018).

4. B. Birich, S. El Hajjaji, N. Ait Daoud, R. Bencheikh Soulaymani, M. Ghandi, N. Badrane, A selective method for quantification of diazinon in human plasma by GC-MS. Ann Biol Clin, 78, 617-622 (2020).

5. S. Onil, Réflexions sur l'utilisation des pesticides en milieu urbain. Québec, l'institut national de santé publique du Québec, Canada, (2002). Document déposé à sante.com

6. D. Boucaud-Maitre, M. O. Rambourg, S. SinnoTellier, E. Puskarczyk, X. Pineau, M. Kammerer, J. Langrand, and al. Human exposure to banned pesticides reported to the French Poison Control Centers: 2012-2016. Environ. Toxicol. Phar, 69, 51-56 (2019),

7. S. Achour, A. Khattabi, N. Rhalem, L'intoxication par les pesticides chez l'enfant au Maroc: profil épidémiologique et aspects pronostiques (19902008), Santé Publique, 23 195-205 (2011).

8. Detsouli et al., Epidemiology of acute pesticide poisoning in Morocco: a 7-year retrospective, J. Mater. Environ. Sci., 8 4234-4239 (2017).

9. A. Bouaziz, M. Mongalgi, A. Debbabi. Les intoxications aiguës chez l'enfant Tunisien (Étude analytique de cas hospitalisés dans un service de pédiatrie générale). Rev Maghr Pédiatrie 4, 5-10 (1994).

10. M. Ait El Cadi, A. Mezzane, B.Meddah, Y. Khabbal, L. Idrissi. Fatal pesticides poisoning in Morocco (2000-2005). Anna. Tox. Anal. 20, 73-77 (2008).

11. A. Derkaoui, A. Elbouazzaoui, N. Elhouari, S. Achour, S. Labib, H., Sbai, M. Harrandou, M. Khatouf, N. Kanjaa, Severe acute poisoning by organophosphorus pesticides: report of 28 cases. Pan Afric. medic. (2011).

12. K. Soltaninejad, M. Faryadi, F. Sardari, Acute pesticide poisoning related deaths in Tehran during the period 2003-2004. J foren leg med, 14(6), 352354. (2007).

13. P. Nisse, Intoxications par les produits phytopharmaceutiques, Traité de toxicologie médico-judiciaire, Elsevier Health Sciences (2012)

14. W. Naksen, T. Prapamontol, A. Mangklabruks, S. Chantara, P. Thavornyutikarn, M. G.Robson, P..B. Ryan, D B. Barr, P. Panuwet, A single method for detecting 11 organophosphate pesticides in human plasma and breastmilk using GC-FPD, J Chrom. B. 1025, 92-104 (2016)

15. S. Savin, B. Cartigny, N. Azaroual, L. Humbert, M. Imbenotte, D. Tsouria, M. Lhermitte, $1 H$ NMR Spectroscopy and GC-MS Analysis of $\alpha$-Chioralose. Application to Two Poisoning Cases. J anal tox, 27(3), 156-161. (2003).

16. G. Hoizey, A. Muckensturm M. Chèze, M. Deveaux, Chloralose analysis in a criminal case. Toxic Anal Cliniq, 31(2), S38-S39. (2019).

17. M. Zhioua, N. Kouraichi, M. Makhlouf, A. Benzarti, F. Riahi, M. Hamdoun, Acute Chloralose Poisoning: 752 Observations. J Med légal droit Med, 51(7), 343 